\title{
Maltrato por omisión. Comentario a la Sentencia no 338/2014, de 28 de octubre de 2014, del Juzgado de lo Penal no 1 de Santander ${ }^{1}$.
}

\section{Sonia Pérez Elicegui ${ }^{2}$}

\section{Introducción.}

La Sentencia número 338/14, dictada por el Juzgado de lo Penal número 1 de Santander el día 28 de octubre de 2014, en Procedimiento Abreviado 383/13, es una de las pocas Sentencias condenatorias de maltrato por omisión a animal doméstico dictadas en España ${ }^{3}$.

La Sentencia a la que nos referimos condena, por la comisión del delito de maltrato a animal doméstico tipificado en el artículo 337 del Código Penal ${ }^{4}$, a la pena de seis meses de prisión e inhabilitación especial durante dos años para el ejercicio de la profesión, oficio o comercio que tenga relación con los animales.

\section{Hechos probados en la sentencia.}

Queda probado y así se declara, que los acusados R.R.G. y A.F.R., el día 29 de julio de 2008, adoptaron de la Asociación de Protección y Adopción Canina - ASPACAN dos perros: uno de nombre Robin, de la raza denominada "Los Osos de Carelia", y otro llamado Aker, de raza "Villano de las Encartaciones". Ambos fueron entregados con contrato de adopción, número de chip y cartilla de control veterinario.

Los condenados trasladaron a los animales a un cobertizo en la localidad de Treto (Cantabria), donde los mantuvieron permanentemente atados a una corta cadena, sin

\footnotetext{
${ }^{1}$ http://www.derechoanimal.info/bbdd/Documentos/1499.pdf

2 Abogada. Letrada de la acusación particular en este procedimiento, ejercida por la asociación ASPACAN.

${ }^{3}$ Vid. REQUEJO CONDE, C. “Abandono. Comentario a la Sentencia 135/10 del Juzgado de lo Penal no 4 de Bilbao (Bizkaia) de 25 de marzo de 2010". http://www.derechoanimal.info/esp/page/1462/abandono-comentario-a-la-sentencia-135or10-deljuzgado-de-lo-penal-n\%C2\%BA-4-de-bilbao-\%28bizkaia\%29-de-25-de-marzo-de-2010

${ }^{4}$ http://www.derechoanimal.info/bbdd/Documentos/839.doc
} 
apenas agua ni comida, rodeados de excrementos y sin recibir cuidados de desparasitación o asistencia veterinaria, ni tan siquiera la vacunación reglamentaria.

En tales circunstancias estuvieron los animales hasta comienzos del mes de agosto de 2011, fecha en la que los representantes de ASPACAN acudieron a rescatarlos y llevarlos a la clínica veterinaria. Robin falleció a las pocas horas, aquejado de una cardiomiopatía dilatada canina motivada por la presencia de parásitos intestinales no tratados previamente, así como por la situación de abandono generalizado que sufría. Por su parte, Aker mostraba una marcada delgadez y atrofia muscular, sobre todo en las extremidades posteriores, así como parasitosis intestinal, que causaban un dolor insoportable al animal. Afortunadamente para él, pasado un tiempo pudo recuperarse, y en la actualidad es un perro que respira felicidad por los cuatro costados.

“(...) de la prueba practicada tanto de los testigos aportados por la acusación como por la testifical practicada ponen de relieve la concreta situación en la que los acusados dejaron a los animales, la ausencia absoluta de cuidados y la situación en la que se encontraban que les impedía el movimiento y les limitaba de manera extrema incluso acceder al agua y los escasos alimentos de los que podían disponer debiendo señalarse que uno de los animales murió escaso tiempo después de la intervención y en cuanto al que sobrevivió estaba en tan lamentables condiciones pudiendo definirse su estado de dramático tanto en los aspectos físico como sanitario."

\section{Fundamentos de Derecho.}

Los hechos declarados probados son constitutivos de un delito de maltrato animal doméstico previsto y penado en el artículo 337 del Código Penal, conforme al cual:

"El que por cualquier medio o procedimiento maltrate injustificadamente a un animal doméstico o amansado, causándole la muerte o lesiones que menoscaben gravemente su salud, será castigado con la pena de tres meses a un año de prisión e inhabilitación especial de uno a tres años para el ejercicio de profesión, oficio o comercio que tenga relación con los animales."

Tal como expone el juzgador en esta Sentencia, este precepto requiere para su aplicación objetiva el cumplimiento de varios elementos:

10) En primer lugar, no cabe cualquier tipo de maltrato, sino únicamente el más transcendente: tiene que provocar o bien la muerte, o bien lesiones que produzcan un grave menoscabo físico. Aparte de estos casos, cualquier otro tipo de maltrato será 
atípico desde el punto de vista penal, si tampoco puede encuadrarse en el artículo 632.2 del Código Penal ${ }^{5}$ (falta de maltrato cruel).

20) En segundo lugar, para estar ante un delito de maltrato del artículo 337, el animal al que se maltrata ha de caracterizarse por ser doméstico o amansado (a diferencia del citado artículo 632.2, que se refiere a domésticos, pero también como "a cualesquiera otros en espectáculos públicos no autorizados".

3o) En tercer y último lugar, el maltrato mortal o gravemente lesivo ha de producirse injustificadamente.

Todos estos elementos concurren en el presente caso, puesto que el maltrato infligido a estos animales, por omisión del deber de cuidado de los mismos, se configura como transcendente, al haber sido la causa que provocó la muerte en uno de ellos y lesiones de importante notoriedad y gravedad en el otro.

\section{Conclusiones.}

Los hechos enjuiciados y condenados en este procedimiento judicial son sólo uno de tantos casos de maltrato que, bien por acción bien por omisión, se producen en nuestro país, con el resultado graves lesiones o incluso la muerte de los animales implicados.

Frente a este tipo de supuestos, tristemente frecuentes, la legislación penal española aún se encuentra por detrás de otros ordenamientos jurídicos de nuestro entorno. Así, por ejemplo, la legislación alemana castiga con pena de prisión de tres años a quien cause a un animal vertebrado graves dolores o sufrimientos ${ }^{6}$; en Suiza, el maltrato se encuentra tipificado desde $1978^{7}$; y en Inglaterra los animales se protegen penalmente desde el siglo XIX ${ }^{8}$.

En España, desde que fue tipificado por primera vez el maltrato animal en el año 2003, mediante la Ley Orgánica 15/2003, el camino ha sido largo y tortuoso, jalonado de un gran número de proyectos y anteproyectos. Gracias a la reforma del Código Penal acometida a

\footnotetext{
${ }^{5}$ http://www.derechoanimal.info/bbdd/Documentos/839.doc

6 Tierschutzgesetz, 1972. § 17

7 Loi fédérale du 9 mars 1978 sur la protection des animaux (LPA). En la actualidad, se encuentra vigente la Ley de 16 de diciembre de 2005 (última modificación en mayo de 2014).

${ }^{8}$ Martin Act de 22 de julio de 1822.
} 
finales del año 2010, y que modificó el artículo 337, se suprimió el requisito de "ensañamiento" ${ }^{\prime 9}$ como principal elemento diferenciador con carácter general de la conducta que pudiera constituir delito o falta, de modo que la calificación de la conducta como delito recaerá sobre todo en el resultado: muerte del animal, o lesiones graves. La supresión de este requisito del tipo penal del artículo 337 supuso la eliminación de un importante obstáculo que venía existiendo para la condena de casos de maltrato animal, y más aún en los supuestos en los que dicho maltrato era ejercido por omisión: perros abandonados sin comida ni agua, explotaciones ganaderas con animales sin atender, etc.

La consideración jurisprudencial de que el delito de maltrato también puede ser cometido por omisión, es sin duda otro importante avance en la línea de una mayor protección penal de los animales. Esta Sentencia contribuye a ello, a que los Jueces y Tribunales empiecen a considerar como delito también la conducta de maltrato en forma omisiva. Y es que a lo largo de los años ha sido habitual encontrarnos con una doctrina y jurisprudencia contrarias y reticentes a admitir un delito de maltrato a animal doméstico por omisión, por muy crueles o brutales que hubieran sido las conductas. Aunque es cierto que, con pronunciamientos como éste, se observa un cambio en dicha corriente, sería muy necesaria una nueva reforma que la concretase e incluyese explícitamente la modalidad de omisión para el delito de maltrato animal.

En todo caso, es ésta una Sentencia ante la que debemos de felicitarnos, por cuanto que supone un importante avance en la protección de los animales. Lástima que la misma llegue tarde para Robin y Aker, quienes un día cambiaron su experiencia de abandono y el refugio en la protectora por la ilusión de una vida mucho más feliz, y que finalmente encontraron en su camino unos seres carentes de sentimientos y de humanidad.

\footnotetext{
${ }^{9}$ El art. 139.3 CP se refiere al ensañamiento como agravante específica del asesinato con la expresión "aumentando deliberada e inhumanamente el dolor del ofendido". El art. 22.5 a, sin utilizar el término, considera circunstancia agravante genérica "aumentar deliberada e inhumanamente el sufrimiento de la víctima, causando a ésta padecimientos innecesarios para la ejecución del delito".
} 